\title{
Pediatric acute kidney injury: new advances in the last decade
}

\author{
Sidharth K. Sethi ${ }^{1}$, Timothy Bunchman ${ }^{2}$, Ronith Chakraborty ${ }^{3}$, Rupesh Raina ${ }^{3,4}$ \\ ${ }^{1}$ Department of Pediatric Nephrology, Kidney Institute, Medanta-The Medicity Hospital, Gurgaon, India \\ ${ }^{2}$ Departments of Pediatric Nephrology and Transplantation, Children's Hospital of Richmond at VCU, Richmond, VA, USA \\ ${ }^{3}$ Akron Nephrology Associates and Cleveland Clinic Akron General Medical Center, Akron, OH, USA \\ ${ }^{4}$ Department of Nephrology, Akron Children's Hospital, Akron, OH, USA
}

Pediatric acute kidney injury (AKI) is a frequently missed complication. AKI has a significant impact on both short- and long-term outcomes in children. Within the last decade, there have been major landmark developments in this field of critical care pediatric nephrology. The topic was searched by two independent researchers using Google Scholar and PubMed and related studies published in the last 10 years. The terms used for the search were 'pediatric acute kidney injury,' 'pediatric acute renal failure,' 'pediatric dialysis,' 'biomarkers,' 'nephrotoxins,' 'nephrotoxicity in children,' and 'pediatric critical care nephrology.' We found that AKI is common in critically ill neonates and children. Among the various definitions, the Kidney Disease: Improving Global Outcomes (KDIGO) definition is most commonly used. In addition, it is imperative to risk stratify sick children at admission in the hospital to predict AKI and worse outcomes as this aids in early management. There are now major landmark trials that describe the epidemiology, prevention, and management guidelines in this field and health care professionals need to be aware they should diagnose AKI early. Overall, this review highlights the landmark studies in the last decade and shows that early diagnosis and management of AKI in 'at risk' children can improve outcomes.

Keywords: Acute kidney injury; Biomarkers; Critical care; Dialysis

\section{Introduction}

Acute kidney injury (AKI) is a common complication, affecting almost one-third of critically sick children and also noncritically ill children admitted to wards [1,2]. In the last decade, there has been a better understanding of outcomes in the field of pediatric AKI, which include higher morbidity, increased length of stay, duration of ventilation, and mortality $[3,4]$. There are newer studies on pediatric AKI epidemiology, clearly delineated definitions, newer biomarkers, and new criteria for risk stratification of children admitted in emergency situations. Additionally,

Received: May 13, 2020; Revised: August 19, 2020; Accepted: August 28, 2020

Editor: Hee Gyung Kang, Seoul National University, Seoul, Republic of Korea

Correspondence: Rupesh Raina

Department of Nephrology, Cleveland Clinic Akron General Medical Center and Akron Children's Hospital, 224 West Exchange Street, Akron, OH 44320, USA. E-mail: rraina@akronchildrens.org, raina@akronnephrology.com

ORCID: https://orcid.org/0000-0003-3892-8376

Copyright (C) 2021 by The Korean Society of Nephrology

(a) This is an Open Access article distributed under the terms of the Creative Commons Attribution Non-Commercial and No Derivatives License (http:// creativecommons.org/licenses/by-nc-nd/4.0/) which permits unrestricted non-commercial use, distribution of the material without any modifications, and reproduction in any medium, provided the original works properly cited. 
definitions and the understanding of neonatal AKI have undergone a drastic change due to recent studies [5]. There is now novel research on machines made especially for smaller children with smaller extracorporeal volume [6-8]. This review includes the major advances in the field of pediatric AKI in the last decade that have made a significant impact on learning and practice in this field (Fig. 1). This is a particularly important area of nephrology, where the clinical and translational advances have been performed first in pediatrics, much before the adult nephrology field.

\section{Changing epidemiology of pediatric acute kidney injury}

There is increasing evidence that the incidence and awareness of pediatric AKI is rising. In infants and children undergoing cardiac surgery, the incidence varies from $30 \%$ to $50 \%$ [9-12]. Additionally, it is common in pediatric intensive care units (ICUs) and has an incidence of $10 \%$ to $35 \%$ [13-15]. The rate is higher in children who are ventilated and are on inotropes [16]. AKI is also common in wards, especially in children receiving aminoglycosides and multiple nephrotoxins during their hospital stay $[17,18]$.

The first prospective study on pediatric AKI, the Assessment of Worldwide Acute Kidney Injury, Renal Angina and Epidemiology (AWARE ) study, was done over a 3-month observational period and included 4,683 children [19]. This study showed that AKI was seen in $26.9 \%$ of children, and severe AKI was seen in $11.6 \%$ of children within 7 days of ICU admission. This increase in AKI severity was associated with a stepwise increase in mortality. Additionally, cardiovascular and respiratory disorders had a higher association with severe AKI.

Among the neonate subgroup, the largest retrospective study in the neonatal population, known as Assessment of Worldwide Acute Kidney Injury Epidemiology in Neonates (AWAKEN), was performed in 2017. This study included more than 2,000 newborns in four different countries admitted to the neonatal ICU before 14 days of life, who received intravenous fluids for at least 48 hours. AKI was

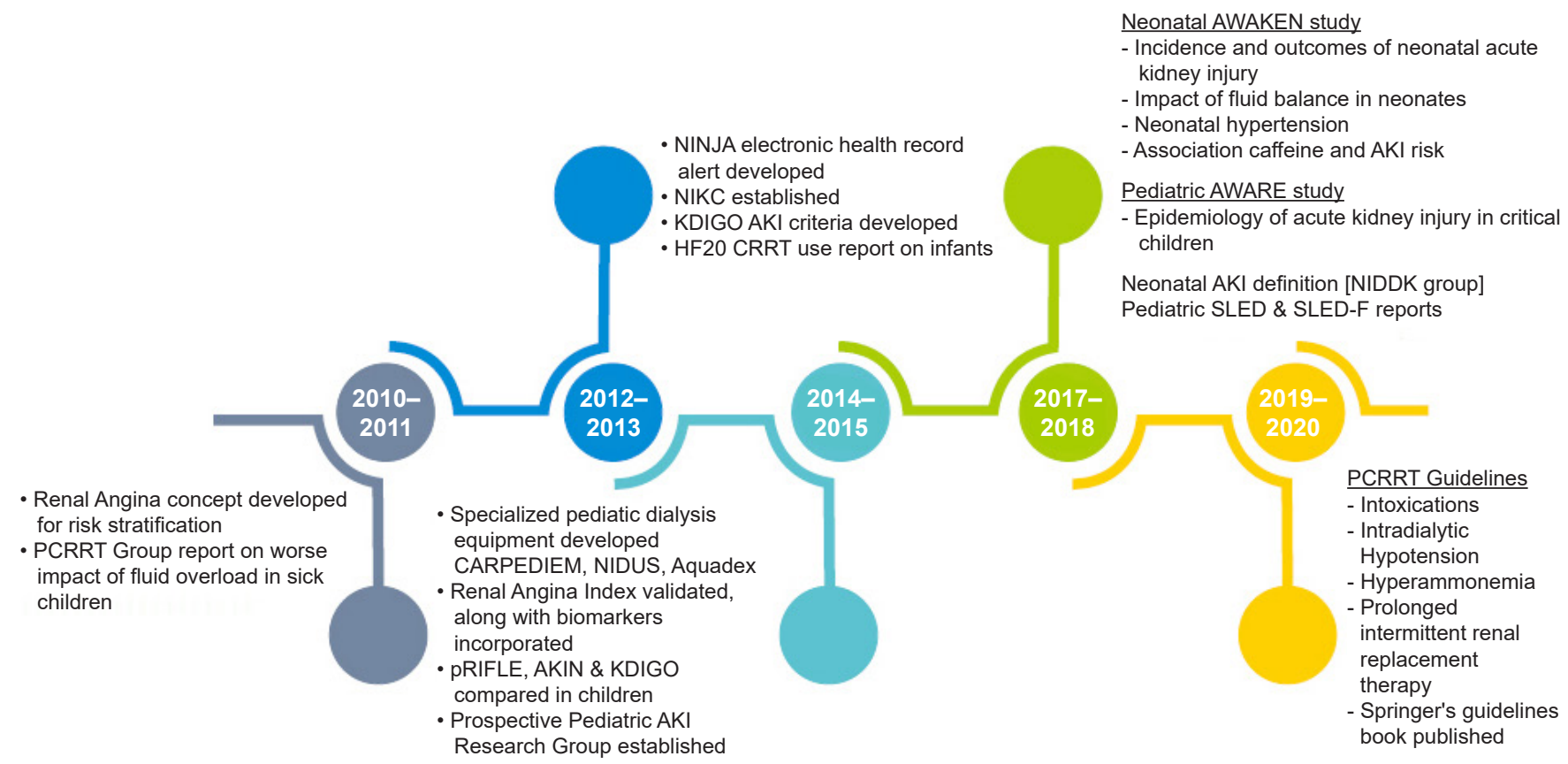

Figure. 1. Timeline of landmark studies in pediatric acute kidney injury (AKI).

AKIN, Acute Kidney Injury Network; AWAKEN, Assessment of Worldwide Acute Kidney Injury Epidemiology in Neonates; AWARE, Assessment of Worldwide Acute Kidney Injury, Renal Angina and Epidemiology; CARPEDIEM, CARdiorenal PEDlatric Emergency Machine; KDIGO, Kidney Disease: Improving Global Outcomes; NIDDK, National Institute of Diabetes and Digestive and Kidney Diseases; NIDUS, Newcastle Infant Dialysis and Ultrafiltration System; NINJA, Nephrotoxic Injury Negated by Just-in-time Action; NKC, Neonatal Kidney Collaborative; PCRRT, Pediatric Continuous Renal Replacement Therapy; pRIFLE, pediatric Risk, Injury, Failure, Loss of kidney function, and End-stage kidney disease; SLED, sustained low-efficiency dialysis; SLED-F, sustained low-efficiency diafiltration. 
seen in $30 \%$ of all newborns and was differently stratified per gestational age, with a higher incidence in extreme preterm birth infants. AKI was also associated with mortality and increased length of stay after adjusting for confounding variables [5].

Additionally, the etiology of AKI varies based on the geographic setting. In the developed world, the setting of AKI has shifted from primary glomerular disorders to hospitalacquired AKI, with common causes being nephrotoxins, critically ill status, postsurgical, posttransplantation, and malignancy $[20,21]$. In the developing world, especially in rural regions, the etiological factors remain as dehydration, sepsis, and hemolytic uremic syndrome [22].

\section{Newer definitions of pediatric acute kidney injury}

The ability of serum creatinine (SCr) to accurately estimate kidney function in a sick child has been problematic. This has resulted in the use of more than 35 definitions of AKI in clinical studies, ranging from changes in $\mathrm{SCr}$ to dialysis requirement. Earlier studies employed nonstandard AKI definitions without any grading (defining AKI as the doubling of SCr), thereby excluding early-stage AKI. Since there was no consensus in definitions, comparisons among studies were difficult, resulting in a wide range of quoted epidemiology, morbidity, and mortality rates within the pediatric AKI literature [23].

The Kidney Disease: Improving Global Outcomes (KDIGO) definition and staging system is the most recent and preferred definition even in pediatric AKI literature [24]. Other classification systems include pRIFLE (pediatric Risk, Injury, Failure, Loss of kidney function, and Endstage kidney disease) and a subsequent modification proposed by the Acute Kidney Injury Network (AKIN) $[25,26]$ (Table 1). Each definition confers its own set of advantages and disadvantages. For example, pRIFLE can diagnose a greater number of mild AKI cases that are usually missed by the other two systems but requires patient height and baseline SCr value, which might not be readily available. In pRIFLE, the estimated creatinine clearance (CCl) is based on the original Schwartz formula to quantitate the change in glomerular filtration rate (GFR) rather than absolute changes in SCr used in the adult RIFLE criteria. Furthermore, the pRIFLE classification has outperformed the AKIN, KDIGO, and conventional grading criteria in predicting AKI in several pediatric patient populations. Zapitelli et al. [27] found that AKI prevalence increased when changes in estimated GFR (eGFR) (pRIFLE) were accounted for rather than changes in SCr (AKIN) in pediatric inpatients. Additionally, Sutherland et al. [23] recently demonstrated notable differences in incidences and substantial disparities in staging resulting from the use of these three definitions on the same cohort of hospitalized children. The AKIN definition appears more specific and does not require height and baseline SCr values; however, it has the most restrictive diagnostic timeframe. The AKIN system, which defines AKI

Table 1. Pediatric acute kidney injury definitions

\begin{tabular}{|c|c|c|c|}
\hline Classification & Staging & Creatinine criteria & Urine output criteria \\
\hline \multirow[t]{5}{*}{ pRIFLE } & Risk & eGFR decreased by $\geq 25 \%$ & $0.5 \mathrm{~mL} / \mathrm{kg} / \mathrm{hr}$ for $8 \mathrm{hr}$ \\
\hline & Injury & eGFR decreased by $\geq 50 \%$ & $0.5 \mathrm{~mL} / \mathrm{kg} / \mathrm{hr}$ for $16 \mathrm{hr}$ \\
\hline & Failure & eGFR decreased by $\geq 75 \%$ (or $<35 \mathrm{~mL} / \mathrm{min} / 1.73 \mathrm{~m}^{2}$ ) & $0.3 \mathrm{~mL} / \mathrm{kg} / \mathrm{hr}$ for $24 \mathrm{hr}$ or anuria for $12 \mathrm{hr}$ \\
\hline & Loss & Persistent failure $>4$ wk & \\
\hline & ESRD & Persistent failure $>3 \mathrm{mo}$ & \\
\hline \multirow[t]{3}{*}{ AKIN } & 1 & $\begin{array}{l}\text { Increase in creatinine of } \geq 50 \% \text { or an absolute increase in creatinine } \\
\text { of } 0.3 \mathrm{mg} / \mathrm{dL} \text { over } 48 \text {-hr period }\end{array}$ & \\
\hline & 2 & Increase in creatinine of $\geq 100 \%$ & \\
\hline & 3 & Increase in creatinine of $\geq 200 \%$ & \\
\hline \multirow[t]{4}{*}{ KDIGO } & 1 & $\begin{array}{l}\text { SCr rise } \geq 0.3 \mathrm{mg} / \mathrm{dL} \text { within } 48 \mathrm{hr} \text { or an increase in creatinine of } \\
\geq 50 \% \text { within } 7 \text { day }\end{array}$ & $>0.5$ and $\leq 1 \mathrm{~mL} / \mathrm{kg} / \mathrm{hr}$ \\
\hline & 2 & Increase in creatinine of $\geq 100 \%$ & $>0.3$ and $\leq 0.5 \mathrm{~mL} / \mathrm{kg} / \mathrm{hr}$ \\
\hline & 3 & $\begin{array}{l}\text { Increase in creatinine of } \geq 200 \% \text { or } \mathrm{SCr} \geq 4 \mathrm{mg} / \mathrm{dL} \text { or receipt of } \\
\text { dialysis or eGFR }<35 \mathrm{~mL} / \mathrm{min} / 1.73 \mathrm{~m}^{2}\end{array}$ & $\leq 0.3 \mathrm{~mL} / \mathrm{kg} / \mathrm{hr}$ \\
\hline & & (neonatal cut-off, $\mathrm{SCr}>2.5 \mathrm{mg} / \mathrm{dL}$ ) & \\
\hline
\end{tabular}

AKIN, Acute Kidney Injury Network; eGFR, estimated glomerular filtration rate; ESRD, end-stage renal disease; KDIGO, Kidney Disease: Improving Global Outcomes; pRIFLE, pediatric Risk, Injury, Failure, Loss of kidney function, and End-stage kidney disease; SCr, serum creatinine. 
as a $\geq 0.3-\mathrm{mg} / \mathrm{dL}$ increase in $\mathrm{SCr}$ within a restrictive 48 -hour period, eliminates the need to estimate $\mathrm{CCl}$. However, the AKIN criteria have not been adequately validated for use in children and the restricted diagnostic timeframe of 48 hours for a rise in SCr may limit its utility.

Although pRIFLE shows a greater sensitivity in detecting AKI than AKIN and KDIGO, all three definitions correlate highly with outcomes (mortality, length of stay in ICU) and enable outstanding inter-stage differentiation [23]. The KDIGO classification is the only one that applies to both children and adults and has a less restrictive diagnostic timeframe than AKIN. Although it does require patient height data (eGFR calculation) for a complete assessment, it is still the preferred definition. The KDIGO AKI criteria have been validated in hospitalized children with both critical and noncritical illness [23,28].

\section{Emerging biomarkers}

$\mathrm{SCr}$ is an indirect and unreliable marker of GFR that can be confounded by renal tubular secretion and numerous other factors such as fluid balance, muscle mass, and medications. Moreover, changes in SCr lag behind the changes in GFR, which can even take several days. In acute settings, it is estimated that SCr rises after a $>50 \%$ decline in GFR [29]. Given the inherent shortcomings of the SCr method, alternative functional and damage biomarkers of AKI have been evaluated.

The use of serum cystatin $\mathrm{C}$ in children as an endogenous marker is well established. Cystatin C is a cysteine protease inhibitor protein, which is produced by all nucleated cells of the body at a constant rate, is freely filtered by the glomerulus, and is catabolized by the proximal tubule. The plasma cells are not affected by sex, age, diet, or muscle mass, and are identical in adults and children over 12 months of age [30]. It outperforms SCr in children for estimation of GFR. Moreover, there is now pediatric data to show that it is an early predictor biomarker of AKI [31].

Genomic and proteomic technologies have revealed novel biomarkers that appear in urine or plasma well before changes in SCr are detected [29]. The most widely studied and validated early biomarker in children is neutrophil gelatinase-associated lipocalin (NGAL) [32]. Most studies of NGAL have been done in children post cardiac surgery, showing that the urine and plasma levels are significantly high in children within 2 hours of cardiac bypass surgery in patients who subsequently develop AKI [33]. Another study done in infants and children undergoing cardiopulmonary bypass established cut-off thresholds and showed strong associations between early NGAL levels and length of hospital stay, duration, and severity of AKI [11,34]. A recent study done on 220 children undergoing cardiac surgery showed that urine NGAL increased in patients within 2 hours, while urine interleukin-18 (IL-18) and urine livertype-fatty acid binding protein levels were elevated within 6 hours, and urine kidney injury molecule- 1 increased at 12 hours. All markers correlated well with severity, clinical outcomes, and, additionally, improved risk prediction [35]. Thus, a panel of biomarkers may help to establish injury timely and plan appropriate timely interventions. Standardized clinical platforms for measurement of plasma and urine NGAL are now available globally.

Recent clinical data in children and adults support the utility and superiority of a new AKI biomarker test, NephroCheck (bioMérieux, Marcy-l'Étoile, France), which detects urinary tissue inhibitor of metalloproteinase 2 (TIMP2) and insulin-like growth factor binding protein 7 (IGFBP7) concentrations and uses their arithmetic product [36,37]. AKI-induced urinary TIMP2/IGFBP7 elevations are not due to stress-induced gene transcription. Rather, increased filtration, decreased tubule reabsorption, and proximal tubule cell TIMP2/IGFBP7 urinary leakage seem to be the most likely mechanisms [38].

There is recent interest in patients who are 'biomarker positive; creatinine negative' which means their urinary or serum early biomarkers are high while $\mathrm{SCr}$ is normal. Two recent studies enrolled more than 4,000 cardiac surgical, critically ill and emergency patients $[39,40]$. Both studies showed almost $>20 \%$ of patients had only elevated NGAL in urine. These 'subclinical AKI' patients in fact had two- to three-fold higher risk of death and need for renal replacement therapy (RRT). Even in patients with very high creatinine, markedly high tubular markers in urine had a worse prognosis.

Hence, NGAL and a panel of urinary or serum biomarkers may help clinicians make an early diagnosis of AKI and plan supportive care early. Moreover, structural biomarkers may further help in reliably classifying AKI in a mechanistic manner. The various functional and structural markers are illustrated in Table 2. 
Table 2. Acute kidney injury (AKI) biomarker-based mechanistic definition

\begin{tabular}{ccl}
\hline Functional marker & Structural marker & Classification \\
\hline- & - & Normal \\
+ & - & Prerenal AKI \\
- & + & Subclinical AKI \\
+ & + & Intrinsic AKI
\end{tabular}

Functional markers include serum creatinine, cystatin $\mathrm{C}$, and other markers of glomerular filtration rate. Structural markers include neutrophil gelatinase associated lipocalin, interleukin-18, and others described in the text above.

\section{Risk stratification at admission: application of 'Renal Angina Index'}

Renal Angina Index (RAI) combines objective parameters of kidney dysfunction (change in $\mathrm{SCr}$ and percent change in fluid overload [\%FO]) and patient characteristics (AKI risk factors) to ascertain renal angina and has been successfully validated as a functional risk stratification tool in critically ill patients with AKI. An RAI of $\geq 8$ within the first 12 hours of ICU admission has shown to entail very high sensitivity and negative predictive value for AKI development or persistence at 72 hours of ICU admission in children [41,42]. RAI is a risk discrimination model that enhances the pretest probability of AKI. It renders context to biomarker measurement and significantly optimizes their predictive performance, akin to the cardiac angina-troponin relationship. RAI has been shown to correlate with an increased need for RRT, prolonged mechanical ventilation, higher oxygenation index, and a higher risk of mortality when compared to children with a negative index score $[43,44]$. RAI entails moderate discrimination for predicting severe AKI prediction, but it improves after incorporation of biomarkers [45].

\section{Clinical examination}

\section{Watch for fluid overload}

Over the last decade, there have been studies in the adult population $[46,47]$ and pediatric population (composed of neonates [48], post cardiac surgery [49], children with multiple organ dysfunction [50], and those on dialysis [51]) that have shown that fluid overload is common and is detrimental in sick patients. It is now well practiced in the intensive care to look at the percent fluid overload in sick children.
A common formula used is:

$\%$ Fluid overload $=\frac{\text { Daily fluid intake }(\mathrm{L})-\text { total output }(\mathrm{L})}{\text { Baseline body weight }(\mathrm{kg})} \times 100$

While fluid overload in children itself is not a direct marker of mortality, the adverse effects lead patients to become vulnerable to an increased risk of morbidity and mortality. It also puts patients at risk of being underdiagnosed with AKI and delays treatment, raises odds for mortality associated with complications, can lead to increased hospital and ICU stays, and can prolong ventilator support in the critically ill population [52].

\section{Furosemide stress test to risk stratify patients}

Clinicians have access to limited tools that predict which patients with early AKI will progress to more severe stages. In early AKI, urine output after a furosemide stress test (FST), which involves intravenous administration of furosemide (1.0 or $1.5 \mathrm{mg} / \mathrm{kg}$ ), can predict the development of stage-3 AKI [53]. There are recent studies which suggest use of this test alone or in combination with biomarkers may predict progression to a severe stage of AKI in sick patients. Using an FST in patients with increased biomarker levels may improve risk stratification [53].

\section{Newer laboratory tests in acute kidney injury differentiation}

Automated urine technology and centralized laboratory testing are becoming the standard for providing urinalysis data to clinicians. It is critical to remember that urine sediment examination remains a time-honored test that provides a wealth of information about the patient's underlying kidney disease. This test performs very favorably as a urinary "biomarker" for a number of acute kidney diseases. Prerenal AKI from true or effective volume depletion is generally not associated with tubular injury/ necrosis. In this setting, urine sediment is usually bland with no/few cells and casts. On the other hand, urine examination is one of the most useful tests in the diagnosis of acute interstitial nephritis and acute nephritic syndrome [54].

In addition to the tests that are commonly used in diagnosing etiology and complications of AKI, urinary indices, especially the fraction excretion of urea (FeUrea), 
have recently been studied. It is well known that the fractional excretion of sodium ( $\mathrm{FeNa}$ ) is $>2 \%$ in children and $>2.5 \%$ in neonates with a higher urine sodium $>30$ meq/L, which suggests tubular damage, e.g., acute tubular necrosis in the AKI setting. However, in certain situations of diuretic therapy or where the patient is on intravenous saline or presents with chronic kidney disease, FeNa may not be reliable. FeNa can then be substituted by FeUrea [55]. A FeUrea $<35 \%$ implies prerenal AKI and FeUrea $>50 \%$ suggests intrinsic AKI. A high FeNa and FeUrea $>35 \%$ have a 95\% negative predictive value for intrinsic AKI [56].

\section{Neonatal acute kidney injury: newer advances}

The major challenges confronted by clinicians involved in the care of neonates with AKI stem from numerous factors; unique renal physiology in term and preterm neonates, lack of a standardized AKI definition, and weight- and gestational age-dependent baseline SCr value in the neonates. Moreover, neonates usually have nonoliguric renal failure, making oliguria an insensitive marker of AKI in this cohort [57]. Neonatal AKI is further confounded by the reflection of maternal SCr levels in neonates for the first 3 days postbirth and the variable decline over days to weeks depending on gestational age [58].

The formation of the Neonatal Kidney Collaborative (NKC) was a giant leap forward which accomplished the heretofore unmet need of neonatal AKI quantification at a global level. The AWAKEN study retrospectively evaluated 2,022 neonates from 24 centers across the globe, which formed the NKC. The group concluded that neonatal AKI is common, with an incidence of $29.9 \%$, and is an independent risk factor for mortality and prolonged hospital stay, independent of demographics, severity of illness, and existing comorbidities. The incidence of AKI was $43 \%$ in patients $<29$ weeks gestation, 18\% in those between 29 and 36 weeks gestation, and $37 \%$ in those $>36$ weeks gestation [5].

Since maternal SCr is transmitted across the placental barrier and its clearance is dependent upon the infant's gestational age, the KDIGO definition was modified in such a manner that baseline SCr was assumed to be the lowest SCr level noted in each infant. Also, the SCr threshold for stage-3 AKI was reduced to $2.5 \mathrm{mg} / \mathrm{dL}$ rather than usual KDIGO threshold of $4 \mathrm{mg} / \mathrm{dL}$ [59].

A recent secondary analysis from AWAKEN also showed that caffeine administration in preterm neonates is associated with reduced incidence and severity of AKI. Further studies should focus on the timing and dosage of caffeine to optimize the prevention of AKI [60]. Other ancillary studies from the same group include a report on the association of AKI and hypertension [61], a study showing the association between AKI and mortality in those with severe neonatal encephalopathy [62], the association of AKI and intraventricular hemorrhage [63], and the association of AKI and chronic lung disease in premature and near term/ term infants $[64,65]$.

\section{Newer machinery for smaller children}

In the last decade, major innovations have been made in designing dedicated machinery with less error for dialysis of newborns and children. The most notable are the Prismaflex HF20 filter (Gambro, Méyzieu, France), the CARdiorenal PEDIatric Emergency Machine (CARPEDIEM; BellcoMedtronic, Mirandola, Italy), the Newcastle Infant Dialysis and Ultrafiltration System (NIDUS); and the Aquadex system (Baxter Corp., Minneapolis, MN, USA).

\section{Prismaflex HF20 filters}

Continuous RRT (CRRT) with Prisma or Prismaflex dialysis machines and M10 (50 mL) or HF20 (55 mL) filters with access via the internal jugular; 6.5 French hemodialysis (HD) catheters may be used. The Prismaflex HF20 set has recently been developed with relatively low circuit volume $(60 \mathrm{~mL})$ and is made of a polyarylethersulfone membrane, which is not associated with bradykinin release syndrome. There have been recent reports of successful use of HF20 filters in unstable infants $[66,67]$.

\section{CARPEDIEM}

The challenge to design RRT equipment specifically intended for newborns and small infants weighing in the range of 1.5 to $10 \mathrm{~kg}$ led to development of the CARPEDIEM system. It received European certification in 2012 after thorough testing. It is a combination of hardware, software, and disposable circuits miniaturized and designed specifically for newborns and small infants with a reduced priming volume ( $27 \mathrm{~mL}$ including filter) with the roller pumps finely regulated by two precision scales accurate to $1 \mathrm{~g}$. It was used for the first time on a neonate in 2013 
and can be used in situations when adequate convective clearance is insufficient due to limited blood supply like in hypercatabolic states, where there is a need for increased dialysis efficiency $[68,69]$.

\section{NIDUS}

NIDUS evolved as a novel HD circuit driven by syringes and uncouples the baby's blood flow capacity from requirements of the dialysis filter. The syringe driven machine repeatedly withdraws 5 to $12.5 \mathrm{~mL}$ aliquots of blood from a single lumen central venous line, passes and returns it across a dialysis filter, and then returns it back to the baby. At a blood flow rate of $20 \mathrm{~mL} / \mathrm{min}$, this processes $5 \mathrm{~mL}$ of blood each minute [8]. A multicenter trial on the use of NIDUS is recruiting babies in the pediatric ICU with a body weight of 0.8 to 7.99 $\mathrm{kg}$, who require continuous dialysis as part of their standard clinical care. The recruitment started in January 2015 and is proposed to continue till December 2020 in the UK [70].

\section{Aquadex}

In order to mitigate the concerns regarding use of large extracorporeal circuits, the Aquadex circuit was adapted to provide prefilter replacement fluid for continuous venovenous hemofiltration (CVVH). The filter is $0.12 \mathrm{~m}^{2}$ and composed of a polysulfone membrane. Ultrafiltration rates of up to $500 \mathrm{~mL} / \mathrm{hr}$ can be achieved for clearance of waste products. A recent pediatric experience of Aquadex has been published on ultrafiltration to provide a range of therapies, including CVVH, prolonged intermittent RRT, and slow continuous ultrafiltration. The group was able to initiate RRT with minimal complications, particularly in critically ill neonates [6].

\section{Better understanding in prevention of pediatric acute kidney injury}

\section{Drugs to prevent acute kidney injury}

\section{Furosemide and bumetanide}

In order to improve urine output in critically ill patients, furosemide has been used to maintain fluid balance. However, studies in adults have not provided any evidence that diuretics improve survival or help in recovery of AKI [71]. Studies in infants undergoing cardiac surgery have shown that furosemide infusion may be used instead of boluses to improve urine output [72]. Recently, bumetanide, a newer loop diuretic, has been used in preterm infants with oliguric AKI. While increasing urine output, there was a rise in SCr, highlighting the potential that loop diuretics can cause nephrotoxicity in this vulnerable population [73].

\section{Low-dose dopamine}

Low-dose dopamine in neonates and pediatric ICU patients failed to demonstrate an improvement in kidney function and urine output [74]. Moreover, there is recent evidence of worsening renal perfusion with this dose itself [75].

\section{Fenoldopam}

A recent study on fenoldopam, a selective dopamine Al receptor agonist that decreases vascular resistance and increases renal blood flow, improved urine output in neonates requiring cardiac surgery with positive fluid balance despite diuretics [76]. Another recent study showed that a higher dose of $1 \mu \mathrm{g} / \mathrm{kg} / \mathrm{min}$ during cardiac surgery may reduce the urinary NGAL and serum cystatin C levels, even without any changes in SCr [77]. However, the data is sparse on this drug.

\section{Theophylline}

During perinatal hypoxia in neonates, adenosine is released, which may cause vasoconstriction in the kidney causing a reduction in GFR [78]. Thus, nonspecific adenosine receptor antagonists, such as aminophylline and theophylline, may help in this specific setting. Three recent randomized trials showed a reduction in $\mathrm{SCr}$ and better urine output in severely asphyxiated neonates who were given a single dose of theophylline [78-81]. Based on these trials, KDIGO also recommends a single dose of theophylline for asphyxiated neonates since they are at risk of AKI [82]. However, there are concerns about neurological side effects, and more so the relevance of these drugs in the era where hypothermia is a standard of care in these neonates.

\section{Rasburicase}

There is a recent interest in rasburicase (a recombinant urate oxidase enzyme) with a retrospective study in seven neonates with AKI. A single bolus of rasburicase reduced SCr, blood urea, and urine output [83]. However, more evidence is needed for the use of this drug in the treatment of AKI in neonates and children. 
Electronic hospital software alerts to help clinicians prevent acute kidney injury

Recently, electronic software integrated within hospital management servers has been successfully used to prevent AKI by alerting clinicians well in time. Nephrotoxic Injury Negated by Just-in-time Action (NINJA) is a prospective AKI monitoring program used in Cincinnati Children's Hospital. It uses an automated program to extract data in real time and flags noncritically ill children who are admitted and are receiving three or more nephrotoxins. These children undergo a daily surveillance of SCr, and the center noted a 38\% reduction in the rate of nephrotoxin exposure and a concomitant $64 \%$ reduction in AKI rates [84]. Recently, a Baby-NINJA initiative in multiple neonatal ICUs reported a reduction in high nephrotoxic medication exposures from 16.4 to 9.6 per 1,000 patient-days $(\mathrm{p}=0.03)$ and a reduction in percentage of nephrotoxic medication-AKI from $30.9 \%$ to $11.0 \%(\mathrm{p}<0.001)[85]$.

\section{Newer advances in dialysis for children}

RRT modalities for pediatric AKI have expanded from peritoneal dialysis (PD), HD to CRRT and sustained lowefficiency dialysis (SLED). Advancements in use of RRT in children have led to a higher standard of care for young and critically ill patients [86]. Since no difference in survival outcomes has been seen with any dialysis method, the optimal RRT modality to be chosen for children with AKI is based on the patient's size, overall clinical status, on the performance of the dialytic modality, and the availability of resources and expertise [87].

PD is the most common and simple method of providing solute and water removal in the ICU. It is easy to perform, can be easily learned, and does not require vascular access or anticoagulation. In a recent worldwide survey by Raina et al., $68.5 \%$ of respondents in developing countries preferred PD for treating infant AKI while only $29.1 \%$ of physicians in developing countries and $22.2 \%$ in developed countries favored PD to treat AKI [88]. Additionally, certain modifications to PD have been made recently to improve ultrafiltration, namely continuous equilibration PD, high volume PD, tidal PD, and continuous flow PD [89].

$\mathrm{HD}$ is the most efficient method of dialysis with rapid solute and fluid removal. It is ideal for managing pulmonary edema, hyperkalemia, intoxications, hyperammonemia, and acute tumor lysis syndrome [90]. However, patient hemodynamic stability is a must for a child to be put on HD. It does require a vascular access, careful evaluation of the extracorporeal blood volume (in the circuit and the dialyzer), and the need for anticoagulation [90]. Recently, the Pediatric Continuous Renal Replacement Therapy Foundation (PCRRT) gave recommendations on how to avoid intradialytic hypotension in children [91].

CRRT is the preferred modality for the management of AKI and fluid overload in critically ill children. It can be used with both or one of the diffusion or convection strategies. It is a complex dialysis modality that requires expertise and systemic heparin or regional citrate anticoagulation. The Prospective Pediatric CRRT Registry Group has published guidelines for dialyzing children with sepsis and multiorgan dysfunction in the last decade $[51,92,93]$.

SLED is an alternative to CRRT in hemodynamically unstable pediatric patients with AKI. It utilizes conventional dialysis machines with low blood pump and dialysate flow rates for $\geq 6$ hours daily. Recently, Sethi et al. [94,95] published a retrospective and prospective experience of SLED in unstable pediatric patients utilizing heparin-free dialysis and prefilter convective replacement fluid.

\section{Conclusion}

Management of AKI is challenging in critical infants and children. Over the past decade, revolutionary landmark studies and machineries have evolved, greatly improving the diagnosis, early detection, and management of renal support in this population. The pediatric nephrology community is working together closely to provide more scientific data to improve renal support in smaller critically sick children.

\section{Conflicts of interest}

All authors have no conflicts of interest to declare.

\section{Authors' contributions}

Conceptualization: SKS, TB, RR

Data curation: All authors

Formal analysis: All authors

Investigation: All authors 
Methodology: All authors

Project administration: All authors

Writing-original draft: SKS, RC, RR

Writing-review \& editing: SKS, RC, RR

All authors read and approved the final manuscript.

\section{ORCID}

Sidharth K. Sethi, https://orcid.org/0000-0002-1516-3393

Timothy Bunchman, https://orcid.org/0000-0002-1781-0398

Ronith Chakraborty, https://orcid.org/0000-0003-1865-9682

Rupesh Raina, https://orcid.org/0000-0003-3892-8376

\section{References}

1. Devarajan P. Pediatric acute kidney injury: different from acute renal failure but how and why. Curr Pediatr Rep 2013;1:34-40.

2. Askenazi D. Evaluation and management of critically ill children with acute kidney injury. Curr Opin Pediatr 2011;23:201-207.

3. Sutherland SM, Ji J, Sheikhi FH, et al. AKI in hospitalized children: epidemiology and clinical associations in a national cohort. Clin J Am Soc Nephrol 2013;8:1661-1669.

4. Sanchez-Pinto LN, Goldstein SL, Schneider JB, Khemani RG. Association between progression and improvement of acute kidney injury and mortality in critically Ill children. Pediatr Crit Care Med 2015;16:703-710.

5. Jetton JG, Boohaker LJ, Sethi SK, et al. Incidence and outcomes of neonatal acute kidney injury (AWAKEN): a multicentre, multinational, observational cohort study. Lancet Child Adolesc Health 2017;1:184-194.

6. Menon S, Broderick J, Munshi R, et al. Kidney support in children using an ultrafiltration device: a multicenter, retrospective study. Clin J Am Soc Nephrol 2019;14:1432-1440.

7. Vidal E, Cocchi E, Paglialonga F, et al. Continuous veno-venous hemodialysis using the cardio-renal pediatric dialysis emergency MachineTM: first clinical experiences. Blood Purif 2019;47:149155.

8. Coulthard MG, Crosier J, Griffiths C, et al. Haemodialysing babies weighing $<8 \mathrm{~kg}$ with the Newcastle infant dialysis and ultrafiltration system (Nidus): comparison with peritoneal and conventional haemodialysis. Pediatr Nephrol 2014;29:18731881.

9. Blinder JJ, Goldstein SL, Lee VV, et al. Congenital heart surgery in infants: effects of acute kidney injury on outcomes. J Thorac Cardiovasc Surg 2012;143:368-374.
10. Tóth R, Breuer T, Cserép Z, et al. Acute kidney injury is associated with higher morbidity and resource utilization in pediatric patients undergoing heart surgery. Ann Thorac Surg 2012;93:1984-1990.

11. Krawczeski CD, Woo JG, Wang Y, Bennett MR, Ma Q, Devarajan P. Neutrophil gelatinase-associated lipocalin concentrations predict development of acute kidney injury in neonates and children after cardiopulmonary bypass. J Pediatr 2011;158:10091015.

12. Li S, Krawczeski CD, Zappitelli M, et al. Incidence, risk factors, and outcomes of acute kidney injury after pediatric cardiac surgery: a prospective multicenter study. Crit Care Med 2011; 39:1493-1499.

13. Schneider J, Khemani R, Grushkin C, Bart R. Serum creatinine as stratified in the RIFLE score for acute kidney injury is associated with mortality and length of stay for children in the pediatric intensive care unit. Crit Care Med 2010;38:933-939.

14. Alkandari O, Eddington KA, Hyder A, et al. Acute kidney injury is an independent risk factor for pediatric intensive care unit mortality, longer length of stay and prolonged mechanical ventilation in critically ill children: a two-center retrospective cohort study. Crit Care 2011;15:R146.

15. Kavaz A, Ozçakar ZB, Kendirli T, et al. Acute kidney injury in a paediatric intensive care unit: comparison of the pRIFLE and AKIN criteria. Acta Paediatr 2012;101:e126.

16. Prodhan P, McCage LS, Stroud MH, et al. Acute kidney injury is associated with increased in-hospital mortality in mechanically ventilated children with trauma. J Trauma Acute Care Surg 2012; 73:832-837.

17. Moffett BS, Goldstein SL. Acute kidney injury and increasing nephrotoxic-medication exposure in noncritically-ill children. Clin J Am Soc Nephrol 2011;6:856-863.

18. Goldstein SL, Kirkendall E, Nguyen H, et al. Electronic health record identification of nephrotoxin exposure and associated acute kidney injury. Pediatrics 2013;132:e756.

19. Kaddourah A, Basu RK, Bagshaw SM, Goldstein SL; AWARE Investigators. Epidemiology of acute kidney injury in critically Ill children and young adults. N Engl J Med 2017;376:11-20.

20. Hui-Stickle S, Brewer ED, Goldstein SL. Pediatric ARF epidemiology at a tertiary care center from 1999 to 2001. Am J Kidney Dis 2005;45:96-101.

21. Duzova A, Bakkaloglu A, Kalyoncu M, et al. Etiology and outcome of acute kidney injury in children. Pediatr Nephrol 2010;25:14531461.

22. Macedo E, Cerdá J, Hingorani S, et al. Recognition and management of acute kidney injury in children: the ISN 0by25 Global Snapshot 
study. PLoS One 2018;13:e0196586.

23. Sutherland SM, Byrnes JJ, Kothari M, et al. AKI in hospitalized children: comparing the pRIFLE, AKIN, and KDIGO definitions. Clin J Am Soc Nephrol 2015;10:554-561.

24. KDIGO Clinical Practice Guideline for acute kidney injury: summary of recommendation statements. Kidney Int Suppl 2012;2:8-12.

25. Mehta RL, Kellum JA, Shah SV, et al. Acute Kidney Injury Network: report of an initiative to improve outcomes in acute kidney injury. Crit Care 2007;11:R31.

26. Plötz FB, Bouma AB, van Wijk JA, Kneyber MC, Bökenkamp A. Pediatric acute kidney injury in the ICU: an independent evaluation of pRIFLE criteria. Intensive Care Med 2008;34:17131717.

27. Zappitelli M, Moffett BS, Hyder A, Goldstein SL. Acute kidney injury in non-critically ill children treated with aminoglycoside antibiotics in a tertiary healthcare centre: a retrospective cohort study. Nephrol Dial Transplant 2011;26:144-150.

28. Selewski DT, Cornell TT, Heung M, et al. Validation of the KDIGO acute kidney injury criteria in a pediatric critical care population. Intensive Care Med 2014;40:1481-1488.

29. Devarajan P. Biomarkers for the early detection of acute kidney injury. Curr Opin Pediatr 2011;23:194-200.

30. Schwartz GJ, Work DF. Measurement and estimation of GFR in children and adolescents. Clin J Am Soc Nephrol 2009;4:18321843.

31. Krawczeski CD, Vandevoorde RG, Kathman T, et al. Serum cystatin $\mathrm{C}$ is an early predictive biomarker of acute kidney injury after pediatric cardiopulmonary bypass. Clin J Am Soc Nephrol 2010;5:1552-1557.

32. Devarajan P. Neutrophil gelatinase-associated lipocalin: a promising biomarker for human acute kidney injury. Biomark Med 2010;4:265-280.

33. Mishra J, Dent C, Tarabishi R, et al. Neutrophil gelatinaseassociated lipocalin (NGAL) as a biomarker for acute renal injury after cardiac surgery. Lancet 2005;365:1231-1238.

34. Parikh CR, Devarajan P, Zappitelli M, et al. Postoperative biomarkers predict acute kidney injury and poor outcomes after pediatric cardiac surgery. J Am Soc Nephrol 2011;22:1737-1747.

35. Krawczeski CD, Goldstein SL, Woo JG, et al. Temporal relationship and predictive value of urinary acute kidney injury biomarkers after pediatric cardiopulmonary bypass. J Am Coll Cardiol 2011;58:2301-2309.

36. Gist KM, Cooper DS, Wrona J, et al. Acute kidney injury biomarkers predict an increase in serum milrinone concentration earlier than serum creatinine-defined acute kidney injury in infants after cardiac surgery. Ther Drug Monit 2018;40:186-194.

37. Hoste EA, McCullough PA, Kashani K, et al. Derivation and validation of cutoffs for clinical use of cell cycle arrest biomarkers. Nephrol Dial Transplant 2014;29:2054-2061.

38. Johnson AC, Zager RA. Mechanisms underlying increased TIMP2 and IGFBP7 urinary excretion in experimental AKI. J Am Soc Nephrol 2018;29:2157-2167.

39. Haase M, Devarajan P, Haase-Fielitz A, et al. The outcome of neutrophil gelatinase-associated lipocalin-positive subclinical acute kidney injury: a multicenter pooled analysis of prospective studies. J Am Coll Cardiol 2011;57:1752-1761.

40. Nickolas TL, Schmidt-Ott KM, Canetta P, et al. Diagnostic and prognostic stratification in the emergency department using urinary biomarkers of nephron damage: a multicenter prospective cohort study. J Am Coll Cardiol 2012;59:246-255.

41. Goldstein SL, Chawla LS. Renal angina. Clin J Am Soc Nephrol 2010;5:943-949.

42. Chawla LS, Goldstein SL, Kellum JA, Ronco C. Renal angina: concept and development of pretest probability assessment in acute kidney injury. Crit Care 2015;19:93.

43. Basu RK, Chawla LS, Wheeler DS, Goldstein SL. Renal angina: an emerging paradigm to identify children at risk for acute kidney injury. Pediatr Nephrol 2012;27:1067-1078.

44. Basu RK, Zappitelli M, Brunner L, et al. Derivation and validation of the renal angina index to improve the prediction of acute kidney injury in critically ill children. Kidney Int 2014;85:659667.

45. Basu RK, Wang Y, Wong HR, Chawla LS, Wheeler DS, Goldstein SL. Incorporation of biomarkers with the renal angina index for prediction of severe AKI in critically ill children. Clin J Am Soc Nephrol 2014;9:654-662.

46. Wiedemann HP, Wheeler AP, Bernard GR. Comparison of two fluid-management strategies in acute lung injury. J Vasc Surg 2006;44:909.

47. Liu KD, Thompson BT, Ancukiewicz M, et al. Acute kidney injury in patients with acute lung injury: impact of fluid accumulation on classification of acute kidney injury and associated outcomes. Crit Care Med 2011;39:2665-2671.

48. Oh W, Poindexter BB, Perritt R, et al. Association between fluid intake and weight loss during the first ten days of life and risk of bronchopulmonary dysplasia in extremely low birth weight infants. J Pediatr 2005;147:786-790.

49. Hazle MA, Gajarski RJ, Yu S, Donohue J, Blatt NB. Fluid overload in infants following congenital heart surgery. Pediatr Crit Care 
Med 2013;14:44-49.

50. Abulebda K, Cvijanovich NZ, Thomas NJ, et al. Post-ICU admission fluid balance and pediatric septic shock outcomes: a risk-stratified analysis. Crit Care Med 2014;42:397-403.

51. Sutherland SM, Zappitelli M, Alexander SR, et al. Fluid overload and mortality in children receiving continuous renal replacement therapy: the prospective pediatric continuous renal replacement therapy registry. Am J Kidney Dis 2010;55:316-325.

52. Raina R, Sethi SK, Wadhwani N, Vemuganti M, Krishnappa V, Bansal SB. Fluid overload in critically Ill children. Front Pediatr 2018;6:306.

53. Koyner JL, Davison DL, Brasha-Mitchell E, et al. Furosemide stress test and biomarkers for the prediction of AKI severity. $J$ Am Soc Nephrol 2015;26:2023-2031.

54. Cavanaugh C, Perazella MA. Urine sediment examination in the diagnosis and management of kidney disease: core curriculum 2019. Am J Kidney Dis 2019;73:258-272.

55. Pépin MN, Bouchard J, Legault L, Ethier J. Diagnostic performance of fractional excretion of urea and fractional excretion of sodium in the evaluations of patients with acute kidney injury with or without diuretic treatment. Am J Kidney Dis 2007;50:566-573.

56. Vanmassenhove J, Glorieux G, Hoste E, Dhondt A, Vanholder $\mathrm{R}$, Van Biesen W. Urinary output and fractional excretion of sodium and urea as indicators of transient versus intrinsic acute kidney injury during early sepsis. Crit Care 2013;17:R234.

57. Brion LP, Fleischman AR, McCarton C, Schwartz GJ. A simple estimate of glomerular filtration rate in low birth weight infants during the first year of life: noninvasive assessment of body composition and growth. J Pediatr 1986;109:698-707.

58. Gallini F, Maggio L, Romagnoli C, Marrocco G, Tortorolo G. Progression of renal function in preterm neonates with gestational age $<$ or $=32$ weeks. Pediatr Nephrol 2000;15:119124.

59. Zappitelli M, Ambalavanan N, Askenazi DJ, et al. Developing a neonatal acute kidney injury research definition: a report from the NIDDK neonatal AKI workshop. Pediatr Res 2017;82:569573.

60. Harer MW, Askenazi DJ, Boohaker LJ, et al. Association between early caffeine citrate administration and risk of acute kidney injury in preterm neonates: results from the AWAKEN study. JAMA Pediatr 2018;172:e180322.

61. Kraut EJ, Boohaker LJ, Askenazi DJ, Fletcher J, Kent AL; Neonatal Kidney Collaborative (NKC). Incidence of neonatal hypertension from a large multicenter study [Assessment of Worldwide Acute Kidney Injury Epidemiology in Neonates-
AWAKEN]. Pediatr Res 2018;84:279-289.

62. Kirkley MJ, Boohaker L, Griffin R, et al. Acute kidney injury in neonatal encephalopathy: an evaluation of the AWAKEN database. Pediatr Nephrol 2019;34:169-176.

63. Stoops C, Boohaker L, Sims B, et al. The association of intraventricular hemorrhage and acute kidney injury in premature infants from the assessment of the worldwide acute kidney injury epidemiology in neonates (AWAKEN) study. Neonatology 2019;116:321-330.

64. Starr MC, Boohaker L, Eldredge LC, et al. Acute kidney injury and bronchopulmonary dysplasia in premature neonates born less than 32 weeks' gestation. Am J Perinatol 2020;37:341-348.

65. Starr MC, Boohaker L, Eldredge LC, et al. Acute kidney injury is associated with poor lung outcomes in infants born $\geq 32$ weeks of gestational age. Am J Perinatol 2020;37:231-240.

66. Liu ID, Ng KH, Lau PY, Yeo WS, Koh PL, Yap HK. Use of HF20 membrane in critically ill unstable low-body-weight infants on inotropic support. Pediatr Nephrol 2013;28:819-22.

67. Santiago MJ, López-Herce J. Prismaflex HF20 for continuous renal replacement therapy in critically ill children. Artif Organs 2011;35:1194.

68. Ronco C, Garzotto F, Brendolan A, et al. Continuous renal replacement therapy in neonates and small infants: development and first-in-human use of a miniaturized machine (CARPEDIEM). Lancet 2014;383:1807-1813.

69. Lorenzin A, Garzotto F, Alghisi A, et al. CVVHD treatment with CARPEDIEM: small solute clearance at different blood and dialysate flows with three different surface area filter configurations. Pediatr Nephrol 2016;31:1659-1665.

70. Walker J. ISRCTN 13787486 Infant kidney dialysis and filtration: the I-KID study [Internet]. London: ISRCTN Registry, 2020 [cited 2020 Apr 3]. Available from: https://doi.org/10.1186/ISRCTN13787486.

71. Cantarovich F, Rangoonwala B, Lorenz H, Verho M, Esnault VL; High-Dose Flurosemide in Acute Renal Failure Study Group. High-dose furosemide for established ARF: a prospective, randomized, double-blind, placebo-controlled, multicenter trial. Am J Kidney Dis 2004;44:402-409.

72. Luciani GB, Nichani S, Chang AC, Wells WJ, Newth CJ, Starnes VA. Continuous versus intermittent furosemide infusion in critically ill infants after open heart operations. Ann Thorac Surg 1997;64:1133-1139.

73. Oliveros M, Pham JT, John E, Resheidat A, Bhat R. The use of bumetanide for oliguric acute renal failure in preterm infants. Pediatr Crit Care Med 2011;12:210-214.

74. Prins I, Plötz FB, Uiterwaal CS, van Vught HJ. Low-dose 
dopamine in neonatal and pediatric intensive care: a systematic review. Intensive Care Med 2001;27:206-210.

75. Lauschke A, Teichgräber UK, Frei U, Eckardt KU. 'Low-dose' dopamine worsens renal perfusion in patients with acute renal failure. Kidney Int 2006;69:1669-1674.

76. Costello JM, Thiagarajan RR, Dionne RE, et al. Initial experience with fenoldopam after cardiac surgery in neonates with an insufficient response to conventional diuretics. Pediatr Crit Care Med 2006;7:28-33.

77. Ricci Z, Luciano R, Favia I, et al. High-dose fenoldopam reduces postoperative neutrophil gelatinase-associated lipocaline and cystatin C levels in pediatric cardiac surgery. Crit Care 2011; 15:R160.

78. Jenik AG, Ceriani Cernadas JM, Gorenstein A, et al. A randomized, double-blind, placebo-controlled trial of the effects of prophylactic theophylline on renal function in term neonates with perinatal asphyxia. Pediatrics 2000;105:E45.

79. Lynch BA, Gal P, Ransom JL, et al. Low-dose aminophylline for the treatment of neonatal non-oliguric renal failure-case series and review of the literature. J Pediatr Pharmacol Ther 2008;13:80-87.

80. Bakr AF. Prophylactic theophylline to prevent renal dysfunction in newborns exposed to perinatal asphyxia: a study in a developing country. Pediatr Nephrol 2005;20:1249-1252.

81. Bhat MA, Shah ZA, Makhdoomi MS, Mufti MH. Theophylline for renal function in term neonates with perinatal asphyxia: a randomized, placebo-controlled trial. J Pediatr 2006;149:180184.

82. Khwaja A. KDIGO clinical practice guidelines for acute kidney injury. Nephron Clin Pract 2012;120:c179-c184.

83. Hobbs DJ, Steinke JM, Chung JY, Barletta GM, Bunchman TE. Rasburicase improves hyperuricemia in infants with acute kidney injury. Pediatr Nephrol 2010;25:305-309.

84. Goldstein SL, Mottes T, Simpson K, et al. A sustained quality improvement program reduces nephrotoxic medicationassociated acute kidney injury. Kidney Int 2016;90:212-221.

85. Stoops C, Stone S, Evans E, et al. Baby NINJA (Nephrotoxic Injury Negated by Just-in-Time Action): reduction of nephrotoxic medication-associated acute kidney injury in the neonatal intensive care unit. J Pediatr 2019;215:223-228.

86. Sethi SK, Bunchman T, Raina R, Kher V. Unique considerations in renal replacement therapy in children: core curriculum 2014. Am J Kidney Dis 2014;63:329-345.

87. Sethi SK, Chakraborty R, Joshi H, Raina R. Renal replacement therapy in pediatric acute kidney injury. Indian J Pediatr 2020; 87:608-617.

88. Raina R, Chauvin AM, Bunchman T, et al. Treatment of AKI in developing and developed countries: an international survey of pediatric dialysis modalities. PLoS One 2017;12:e0178233.

89. Kim YH, Resontoc LP. Peritoneal dialysis in critically ill children. In: Deep A, Goldstein SL, eds. Critical care nephrology and renal replacement therapy in children. New York: Springer, 2018. p. 307-323.

90. Raina R, Lam S, Raheja H, et al. Pediatric intradialytic hypotension: recommendations from the Pediatric Continuous Renal Replacement Therapy (PCRRT) Workgroup. Pediatr Nephrol 2019;34:925-941.

91. Raina R, Grewal MK, Blackford M, et al. Renal replacement therapy in the management of intoxications in children: recommendations from the Pediatric Continuous Renal Replacement Therapy (PCRRT) workgroup. Pediatr Nephrol 2019;34:2427-2448.

92. Fleming GM, Walters S, Goldstein SL, et al. Nonrenal indications for continuous renal replacement therapy: a report from the Prospective Pediatric Continuous Renal Replacement Therapy Registry Group. Pediatr Crit Care Med 2012;13:e299.

93. Symons JM, Chua AN, Somers MJ, et al. Demographic characteristics of pediatric continuous renal replacement therapy: a report of the prospective pediatric continuous renal replacement therapy registry. Clin J Am Soc Nephrol 2007;2:732-738.

94. Sethi SK, Sinha R, Jha P, et al. Feasibility of sustained low efficiency dialysis in critically sick pediatric patients: a multicentric retrospective study. Hemodial Int 2018;22:228-234.

95. Sethi SK, Bansal SB, Khare A, et al. Heparin free dialysis in critically sick children using sustained low efficiency dialysis (SLEDD-f): a new hybrid therapy for dialysis in developing world. PLoS One 2018;13:e0195536. 